\title{
Postpartum Health among Rural Zambian Women
}

\author{
Marieke Lagro ${ }^{1,2}$, Agnes Liche', Theresa Mumba', Ruth Ntebeka ${ }^{1}$ and Jos van Roosmalen ${ }^{3}$
}

\begin{abstract}
Health problems after childbirth have received little attention compared to maternal morbidity in the antenatal period and during labour. We conducted a hospital-based study to investigate postpartum health problems in rural Zambian women. Health problems are very common: $84 \%$ of the 620 study participants reported at least one health problem. The majority of women who experienced a health problem took action to relieve the complaint. High vaginal swabs were used to diagnose a genital tract infection. Seventeen per cent of the swabs were abnormal; most women with abnormal result showed no symptoms of genital tract infection. Ninety three per cent of women with symptoms suggestive of a genital tract infection did not seek medical attention. Further research is needed to estimate the impact of self-reported health problems on women's daily lives. Women should be educated on specific conditions that require medical care. More information is also needed on the prevalence of sexually transmitted infections in antenatal and postpartum women including the feasibility of mass screening and treatment in this group of women. (Afr J Reprod Health 2003; 7[3]: 41-48)
\end{abstract}

\section{RÉSUMÉ}

La santé du post-partum chez les femmes zambiennes rurales. Les problèmes de la santé de l'après accouchement n'ont attiré que très peu d'attention par rapport à la morbidité maternelle dans la période prénatale et pendant l'accouchement. Nous avons mené cette étude basée sur l'hôpital pour étudièr les problèmes liés à la santé du post-partum chez les femmes zambiennes rurales. Les problèmes de la santé sont communs: 84\% parmi les 620 femmes enquêtées avaient au moins un problème de santé. La majorité des femmes qui avaient un problème de santé ont pris des mesures pour alléger la plainte. Une infection de faisseau génital a été diagnostiqué à l'aide des prélèvement vaginaux de haut degré. Dix sept pour cent des prélèvements étaient anormaux; la plupart des femmes qui avaient des résultats anormaux n'avaient pas de symptômes de l'infection du faisseau génital. Quatre-vingt-trois pour cent des femmes qui avaient des symptômes qui indiquaient l'infection du faisseau génital n'ont pas recherché des soins médicaux. En plus, il faut davantage des recherches pour évaluer l'impact des problèmes de la santé signalés par soi-même sur la vie quotidienne des femmes. Il faut sensibiliser les femmes aux conditions particulières qui exigent des soins médicaux. Il faut encore des rensiegnements sur la prévalence des infections sexuellement transmissibles chez les femmes en grossesse et chez celles qui viennent d'accoucher, y compris la possibilité d'un dépistage et d'un traitement systématique des femmes de ce groupe. (Rev Afr Santé Reprod 2003; 7[3]: 41-48)

KeY Words: Postpartum morbidity, genital tract infection, health-seeking behaviour, hospital-based study, Zambia

${ }^{1}$ Mpongwe Mission Hospital, Mpongwe, Copperbelt Province, Zambia. ${ }^{2}$ Department of Obstetrics and Gynaecology, Erasmus University

Medical Centre, Rotterdam, The Netherlands. ${ }^{3}$ Department of Obstetrics, Leiden University Medical Centre, Leiden, The Netherlands.

Correspondence: M. Lagro, Tapuitstraat 4b, 3083 WN Rotterdam, The Netherlands. E-mail: mlagro@hotmail.com 


\section{Introduction}

Health problems after childbirth have received little attention compared to maternal morbidity in the antenatal period and during labour. ${ }^{1,2}$ Studies $^{3-6}$ from western countries indicate that health problems after childbirth are common, and although most of these problems are not life-threatening they might influence the well-being of the mother and affect her daily functioning. Data on maternal morbidity in developing countries are sparse and are usually focused on potentially life-threatening complications during antenatal and delivery periods. ${ }^{7-9}$ A few studies ${ }^{10-13}$ from Asia specifically reported problems women experience in the postpartum period and the high prevalence of health problems.

In Mpongwe Mission Hospital, a rural district hospital in Zambia, postpartum health problems are rarely diagnosed. In 1999, 2000 and 2001 approximately $1.5 \%$ of admissions to female and maternity wards were related to postpartum complications, mostly puerperal sepsis. Pregnancyrelated morbidity is a diagnostic category on the hospital management information system (HMIS) registration form for new outpatients. Since the introduction of this system in 1999, very few patients were diagnosed with a pregnancy-related complication. Statistics from the mother and child health clinic $(\mathrm{MCH})$ include postpartum attendance rates, which give no information about problems women experience in the postpartum period. Midwives working at the hospital seem to encounter few puerperal complications. Due to time constraints, however, the midwives usually inquire generally about the woman's health after childbirth and only take a more extensive history when she presents a complaint. We were interested to know if women experienced health problems after childbirth, what specific problems they experienced and if they did anything about these problems.

\section{Subjects and Methods}

The study was conducted from 1st March to 1st December 2001 at Mpongwe Mission Hospital in Mpongwe District, Zambia. In 1996, Ndola Rural District in the Copperbelt Province was divided into three districts and Mpongwe District with a population of 71.915 people is the smallest of them. It however has two first referral hospitals and eleven rural health centres. The other two districts are without a hospital. In 1998, a safe motherhood project started in Mpongwe District. The project provided all health facilities in the district with necessary equipment and trained health workers in essential obstetric care. The health centres deliver very basic obstetric care: they assist with normal deliveries and usually provide oxytocics, antibiotics, anticonvulsants, suturing materials and intravenous fluids. Both hospitals in Mpongwe District provide comprehensive emergency obstetric care. There is no communication or transport system in place between the health centres and the hospital.

Mpongwe Mission Hospital has ninety beds and is both a first referral hospital and a rural health centre. Nine hundred and four pregnant women received antenatal care and 686 women gave birth at the hospital in 2001.

The major source of income for the population is subsistence farming. The rural health centres lie scattered throughout the district with distances ranging from 15 to $140 \mathrm{~km}$ to Mpongwe Mission Hospital. In the study period, tarring of the road from Luanshya, the nearest town $60 \mathrm{~km}$ away, to the turn-off to Mpongwe Development Company, a big farming company in the district, was completed. Mpongwe Mission Hospital is situated along this road. All other roads in the district are dirt roads and transport is usually by foot and bicycle.

\section{Study Design}

The study population consisted of women who attended the hospital within three months after delivery of a live or stillborn baby with a gestational age of more than 22 weeks or weighing more than 500 grams. A three-month period was chosen to minimise recall bias. All midwives, clinical officers and the medical officer in charge were briefed about the study and asked to send eligible women to the study team. This team consisted of two midwives from the mother and child health clinic, one midwife stationed at the maternity ward/family planning clinic and a medical officer who co-ordinated the study. 
All eligible women were provided with detailed information on the contents of the study by one of the team members in order to obtain their consent (oral) to participate. If a woman refused to participate her age, parity, date of delivery, and the reason for refusal were noted.

The women were interviewed by one of the team members using a semi-structured questionnaire that was divided into five parts. In the first part, personal details such as age, parity, antenatal care attendance and residential distance from the hospital were noted. The second part was concerned with place and mode of delivery. Mode of delivery was considered abnormal when there was pre-term labour, signs of intrauterine infection, operative delivery, duration of labour more than 24 hours, episiotomy or third degree perineal tear, retained placenta, early postpartum haemorrhage, stillbirth and early neonatal death. The next section of the questionnaire contained questions on reason for attending the hospital and self-reported complaints. Women were asked if they had experienced a number of specific problems out of a list of sixteen items, what remedies they used for those complaints and when they started normal duties and sexual relations after the problems. To conclude the interview, physical examination and high vaginal swab were done to investigate genital tract infections. The swab was taken by spreading the labia minora and inserting the swab as high as possible into the vagina. Results were defined as abnormal when there were moderate to many puscells present and/or Trichomonas vaginalis was seen and/or gram-negative diplococci were present in the gram stain. Trained laboratory technicians processed and examined all the swabs. The interview and physical examination took about 20-25 minutes.

In January and February 2001 a pilot study was done to test the questionnaire. The results and problems were discussed with team members and adjustments in logistics and the questionnaire were made.

\section{Data Analysis}

Data analysis was undertaken using Epi Info statistical software version 6.04. Mann-Whitney $U$ test was used to compare means and $\mathrm{c}^{2}$-test to compare categorical variables between groups. Distributions were considered significantly different for $\mathrm{p}$-values less than 0.05 .

\section{Results}

In the study period, 641 women attended the hospital within three months after childbirth. The children of 67 women were admitted to the children's ward. Thirteen of these children died within 48 hours of admission. The mothers of the children were not asked to participate in the study because of their infants' serious condition on admission. Another six mothers agreed to participate but were not interviewed before their babies were discharged. We have no information about those nineteen women. Two women declined participation because they were too busy: both of them had delivered in hospital and attended for infant vaccinations. A total of 620 women were included in the study.

\section{Characteristics of Study Population}

The women attended on average thirty days after childbirth. Their mean age was 24.8 years and 135 $(22 \%)$ of them had delivered their first child. The majority of participants $(66 \%)$ lived within three hours walking distance from the hospital. Antenatal care was attended at least once by 493 (97\%) women and $411(66 \%)$ gave birth at a health facility. Twenty per cent of the deliveries were defined as abnormal. The most common reason for visiting the hospital was infant vaccination (41\%), followed by postpartum care $(29 \%)$ and a combination of both $(11 \%)$. Only twenty three women (4\%) attended the hospital for a specific health problem: nineteen women complained of abdominal pain and four of malaria. Only seven of the 620 women were admitted in the postpartum period, four of them for a pregnancy-related cause.

\section{Health Problems}

We made a difference between problems women "spontaneously" reported after being asked if they had experienced any problems after childbirth (selfreported problems) and complaints women expressed when they were specifically questioned (list of sixteen complaints). 
Three hundred and twenty six (58\%) of the women spontaneously reported a complaint: 233 (38\%) reported one problem, 95 (15\%) two problems and $33(5 \%)$ more than two problems (Table 1). The most common self-reported problems were abdominal pain, abdominal pain in combination with backache, and backache alone (Table 3).

Out of 620 women, 519 (84\%) confirmed that they (had) suffered at least one health problem out of a list of sixteen. Seventy six $(12 \%)$ reported one complaint, 97 (16\%) two complaints and $346(56 \%)$ more than two complaints ('Table 2). For 36 women, we only have information about the number of complaints but not the type. Lower abdominal pain, fever, dysuria, constipation, fatigue, dizziness, headache and backache were the most commonly reported complaints among 483 women (Table 3).

Table 1 Number of Self-Reported Health Problems in Postpartum Women attending Mpongwe Mission Hospital

\begin{tabular}{lcc}
\hline $\begin{array}{l}\text { Number of } \\
\text { self-reported problems }\end{array}$ & $\begin{array}{c}\text { Frequency } \\
\mathbf{N =} \mathbf{6 2 0}\end{array}$ & Percentage \\
\hline 0 & 259 & 42 \\
1 & 233 & 38 \\
2 & 95 & 15 \\
3 & 24 & 4 \\
$>4$ & 9 & 1 \\
\hline
\end{tabular}

\begin{tabular}{lcc} 
Table 2 & $\begin{array}{l}\text { Number of Complaints from List of } \\
\text { Health Problems in Postpartum } \\
\text { Women attending Mpongwe Mission } \\
\text { Hospital }\end{array}$ \\
Humber of complaints Frequency & Percentage \\
Nrom list & N = 620 & \\
\hline 0 & 101 & 16 \\
1 & 76 & 12 \\
2 & 97 & 16 \\
3 & 76 & 12 \\
4 & 87 & 11 \\
5 & 67 & 19 \\
$\geq 6$ & 116 &
\end{tabular}

Table 3 Type of Complaints in Postpartum Women attending Mpongwe Mission Hospital

\begin{tabular}{lcc}
\hline $\begin{array}{l}\text { Type of complaints } \\
\text { from list }\end{array}$ & $\begin{array}{c}\text { Frequency } \\
\text { N }=483\end{array}$ & Percentage \\
\hline Abdominal pain & 362 & 75 \\
Backache & 266 & 55 \\
Headache & 226 & 47 \\
Fever & 200 & 42 \\
Dizziness & 167 & 35 \\
Vaginal discharge & 148 & 31 \\
Fatigue & 147 & 31 \\
Dysuria & 115 & 24 \\
Constipation & 97 & 20 \\
Heart palpitations & 50 & 10 \\
Abnormal vaginal bleeding & 36 & 7 \\
Breast problems & 27 & 6 \\
Oedema & 8 & 2 \\
Incontinence & 6 & 1 \\
Faecal incontinence & 1 & 0.2 \\
Other & 69 & 14 \\
\hline
\end{tabular}

Table 4 Type of Action Taken to Alleviate Health Problem by Postpartum Women attending Mpongwe Mission Hospital $(\mathrm{N}=270)$

\begin{tabular}{lcc}
\hline Action taken & Frequency & Percentage \\
\hline Pain killer & 89 & 33 \\
Hot compresses & 49 & 18 \\
African medicine & 32 & 12 \\
Consulted health professional & 70 & 26 \\
Sought relative's advice & 28 & 10 \\
Others & 32 & $12^{*}$ \\
\hline \multirow{2}{*}{ Total is more than 100\% because some women took more than one } \\
$\quad$ action.
\end{tabular}




\section{Health-Seeking Behaviour}

The majority (59\%) of women with a self-reported complaint had taken action to relieve the problem. Sixty eight $(32 \%)$ took a pain killer, $32(15 \%)$ used hot compresses, 26 (12\%) used African medicine, 61 (29\%) sought advice from a professional health worker, while $20(9 \%)$ sought advice from a relative (Table 4).

\section{Physical Examination}

Most women appeared healthy on first sight. On physical examination, 105 of them showed abnormal signs: fever (3), hypertension (12), pallor (12), uterine tenderness (26) and pus-like discharge or breakdown of the episiotomy/perineal tear (21). In 27 women a combination of abnormal signs was present, of which a tender uterus with an abnormal vulva examination was the most common (10).

\section{Genital Tract Infection}

High vaginal swab results were not available for 107 women (17\%): results were missing or swabs were not performed because they were out of stock. Swabs were abnormal in 89 of the $513(17 \%)$ swabs. Only forty women $(49 \%)$ returned to the hospital for treatment. A combination of lower abdominal pain, fever and foul smelling vaginal discharge was suggestive of puerperal infection. This combination of symptoms was present in $58(9 \%)$ women. On physical examination only $7(12 \%)$ had a fever, 6 $(10 \%)$ had tender uterus and $12(21 \%)$ vaginal discharge. In 15 out of 53 women (28\%) the results of the high vaginal swab were abnormal.

Table 5 Genital Tract Infections in Postpartum Women attending Mpongwe Mission Hospital

\begin{tabular}{lrrr}
\hline High vaginal swab & \multicolumn{3}{c}{ Symptoms } \\
& No & Yes & Total \\
\hline Normal & 386 & 38 & 424 \\
Abnormal & 74 & 15 & 89 \\
Subtotal & 460 & 53 & 513 \\
Missing & 102 & 5 & 107 \\
& 562 & 58 & 620 \\
\hline
\end{tabular}

\section{Daily Activities}

We interviewed 252 women six weeks or more after childbirth. In this group, 196 (78\%) were performing all their daily household activities like washing, cooking, sweeping and grinding maize. The majority started those activities within two weeks after childbirth. Only 68 (27\%) women had resumed sexual relations with their partners and more than $90 \%$ in the two months following childbirth.

\section{Discussion}

The results from this study indicate that health problems after childbirth are common. Fifty eight of the women "spontaneously" reported a health problem and $84 \%$ said they experienced at least one complaint out of a list of sixteen. This is in accordance with results from other studies, ${ }^{10-13}$ although the rates of reported health problems vary. In an Indian community-based survey, $23 \%$ of 2300 respondents reported problems in the postpartum period. ${ }^{10,11} \mathrm{~A}$ study ${ }^{12}$ in Sri Lanka among 600 women showed that $89 \%$ reported one or more symptoms of ill health during the puerperium. In Dhaka, Bangladesh, three quarters of the study population reported a nontrivial illness during the first six weeks postpartum. ${ }^{13}$

All these studies are population-based and were conducted in Asia. Our study is hospital-based and the study population might not be representative of postpartum women in Mpongwe District. For example, $66 \%$ of the study population delivered in a health institution, compared to $46 \%$ in the whole of Zambia in $1996 .{ }^{14}$ Antenatal care attendance rate is however the same as the national attendance rate ${ }^{14}$ ( $97 \%$ and $98 \%$ respectively). It is known that women who give birth in a health institution and attend postpartum care have a higher socio-economic status than women who give birth at home and do not attend postpartum care. ${ }^{14}$ We have no information about the socio-economic status of the study participants, but women who visit the hospital for other reasons including child growth monitoring and vaccinations might also have a higher socio-economic status compared to women who do not. The results from this study might either under or overestimate the true figure for health problems in the postpartum period. 
The type of health problems the women reported in this study is comparable with those in other studies, ${ }^{10-13,15}$ but there are large differences in frequency of occurrence. This can be ascribed to the differences in study populations and the methods used to elicit health problems. All studies, including this, used the method of women's self-reported health problems. This method is useful in determining the burden of disease of postpartum morbidity, but it cannot diagnose specific conditions. However, it is the perception of a problem that largely determines health care seeking behaviour and the demand of health care.

Only $4 \%$ of the study population specifically attended hospital for a health problem. Half of the women who reported a health problem took action to alleviate the complaint. A quarter in this group had sought advice from a professional health worker while two thirds used home remedies such as panadol, hot compresses and African medicine. Panadol was the most frequently used drug for abdominal pain and fever. Hot compresses were applied to the abdominal wall to alleviate abdominal cramps and sometimes put in the vagina to stop bleeding. African medicines are herbal concoctions used for a broad range of symptoms. They are smeared on the abdominal wall to relieve abdominal cramps, put into the vagina to stop bleeding and taken orally as a brew for both purposes. The women who did nothing about their complaints regarded them as a part of a normal postpartum period. This attitude might be justified. Nevertheless, we should not assume that women know the relationship between certain complaints and serious postpartum conditions that need medical attention, for example, anaemia and puerperal infection.

Sexually transmitted infections are a major public health problem in many African countries including Zambia. In women aged 15-49 years in Ndola, Zambia, 2.3\% was infected with gonorrhoea and $2.9 \%$ with chlamydia. ${ }^{17}$ The development of postpartum genital tract infection is correlated with maternal gonococcal and chlamydial infections. ${ }^{16}$ Postpartum genital tract infections and sexually transmitted diseases cause serious reproductive morbidity such as infertility, ectopic pregnancy and chronic pelvic pain.
Studies among postpartum women report different prevalence rates for sexually transmitted infections. In 1013 Kenyan women who were tested on the day of labour and seven days postpartum, the prevalence of gonococcal and chlamydial infections was $6.7 \%$ and $20.8 \%$ respectively. ${ }^{16}$ Thirty five per cent of cases with postpartum genital tract infection were attributable to infection with either or both $N$. gonorrboea and C. trachomatis. ${ }^{16}$ Chlamydia and gonorrhoea infection were present in $7.7 \%$ and $3.4 \%$ respectively of 148 Ghanaian postpartum women. ${ }^{18}$ Studies conducted among pregnant women reported higher prevalence rates. At least one sexually transmitted disease was diagnosed in 34\% of urban antenatal women in the Central African Republic $^{19}$ and in $52 \%$ of pregnant rural South African women. ${ }^{20}$

In this study we used high vaginal swabs to diagnose a genital tract infection. Seventeen per cent of the high vaginal swabs were abnormal. Only $17 \%$ of women with an abnormal vaginal swab had symptoms that pointed to a genital tract infection. This confirms the fact that genital tract infections in women can be present without symptoms.

We found that puerperal infection was likely when women reported a combination of three symptoms, namely, lower abdominal pain, fever and foul smelling vaginal discharge. This combination was present in 58 participants $(9 \%)$. Out of these 58 women, 31 could be diagnosed with a puerperal infection after a physical examination and the results of the high vaginal swab were taken into account. Only four women specifically visited the hospital for symptoms of puerperal infection and were diagnosed and treated for this condition. The other women with symptoms suggestive of puerperal infection (54) did not perceive their problems as "alarming" and in need of medical attention.

To control postpartum genital tract infections there is need for an integrated approach, which includes raising awareness among women about signs and symptoms of puerperal infection, treatment of individuals and their partners and preventing sexually transmitted infections. ${ }^{20}$ Mass screening for sexually transmitted infections or treatment of all antenatal and/or postpartum women might be an effective way of reducing the burden of disease. ${ }^{20}$ Before 
introducing mass screening or treatment, more information is needed on the prevalence of sexually transmitted infections in antenatal and postpartum women and about its cost-effectiveness. ${ }^{20}$

\section{Recommendations}

- Women need to be informed that certain signs and symptoms in the postpartum period can indicate a serious condition that needs medical attention.

- Health workers should be aware of health problems in the postpartum period and should use this knowledge in diagnosing and treating serious conditions.

- Further research is needed on the impact of these health problems on women's daily lives.

- To reduce the number of postpartum genital tract infections and its serious reproductive health sequelae, more information is needed on the prevalence of sexually transmitted infections in antenatal/postpartum women and the cost-effectiveness of mass screening.

\section{Acknowledgements}

This study was supported financially by The Netherlands Society of Tropical Medicine and International Health. We wish to thank Mrs. Rose Munkombwe, Mrs. Justina Chizombo, Mrs. Rabecca Siakwezya, Mr. Sparkman Chilyabanyama, Mr. Justin Mwange and other staff of Mpongwe Mission Hospital for their contributions to the study.

\section{REFERENCES}

1. Liskin LS. Maternal morbidity in developing countries: a review and comments. Int J Gynaecol Obstet 1992; 37: 77-87.

2. Postpartum care of mother and newborn: a practical guide. World Health Organization, 1998.

3. Glazener CMA, Abdalla M, Stroud P, Naji S, Templeton A and Russell IT. Postnatal maternal morbidity: extent, causes, prevention and treatment. Br J Obstet Gynaecol 1995; 102: 282287.
4. Albers LA. Health problems after childbirth. $J$ Midwif Women Health 2000; 45: 55-57.

5. Brown S and Lumley J. Maternal health after childbirth: results of an Australian population based survey. Br J Obstet Gynaecol 1998; 105: 156-161.

6. Saurel-Cubizolles M-J, Romito P, Lelong N and Ancel P-Y. Women's health after childbirth: a longitudinal study in France and Italy. Br J Obstet Gynaecol 2000; 107: 1202-1209.

7. Prual A, Huguet D, Garbin O and Rabé G. Severe obstetric morbidity of the third trimester, delivery and early puerperium in Niamey (Niger). Afr J Reprod Health 1998; 2: 10-19.

8. Prual A, Bouvier-Colle M-H, de Bernis L and Bréart G. Severe maternal morbidity from direct obstetric causes in West-Africa: incidence and fatality rates. Bull World Health Organization 2000; 78: 593-602.

9. de Bernis L, Dumont, Bouillin D, Gueye A, Dompnier J-P and Bouvier-Colle M-H. Maternal morbidity and mortality in two different populations in Senegal: a prospective study (MOMA survey). Br J Obstet Gynaecol 2000; 107: 68-74.

10. Bhatia JC. Levels and determinants of maternal morbidity: results from a community based study in Southern India. Int J Gynaecol 1995; 50(suppl): S153-S163.

11. Bhatia JC and Cleland J. Obstetric morbidity in South India: results from a community survey. Sco Sci Med 1996; 43: 1507-1516.

12. De Silva WI. Puerperal morbidity: a neglected area of maternal health in Sri Lanka. Soc Biol 1998; 45: 223-245.

13. Uzma A, Underwood P, Atkinson D and Thackrah R. Postpartum health in a Dhaka slum. Soc Sci Med 1999; 48: 313-320.

14. Nsemulika BG, Phiri DS, Diallo HM, Banda SS, Kalunde Benaya W and Kitahara N. A study of factors associated with maternal mortality in Zambia, 1998. Ministry of Health, Lusaka 1998. 
15. Ransjö-Arvidson AB, Chintu K, N'gandu N, Eriksson B, Susu B, Christensson K and Diwan VK. Maternal and infant health problems after normal childbirth: a randomised controlled study in Zambia. J Epid Comm Health 1998; 52: 385-391.

16. Plummer FA, Laga M, Brunham RC, Piot P, Ronald AR, Bhullar V, Mati JY, Ndinya-Achola JO, Cheang M, Nsanze H. Postpartum upper genital tract infections in Nairobi, Kenya: epidemiology, etiology, and risk factors. J Infect Dis 1987; 156: 92-98.

17. Buvé A, Weiss HA, Laga M, Van Dyck E, Musonda R, Zekeng L, Kahindo M, Anagonou S, Morison L, Robinson NJ and Hayes RJ (For the study group on heterogeneity of HIV epidemics in African cities). The epidemiology of gonorrhoea, chlamydial infection and syphilis in four African cities. AIDS 2001; 15(suppl 4): S79-S88.

18. Bentsi C, Klufio CA, Perine PL, Bell TA, Cles LD, Koester CM and Wang SP. Genital infections with Chlamydia trachomatis and Neisseria gonorbhoea in Ghanaian women. Genitourin Med 1985; 61: 48-50.

19. Blankhart D, Muller O, Gresenguet $G$ and Weis P. Sexually transmitted infections in young pregnant women in Bangui, Central African Republic. Int STD Aids 1999; 10: 609-614.

20. Sturm AW, Wilkinson D, Ndovela N, Bowen S and Connolly C. Pregnant women as a reservoir of undetected sexually transmitted diseases in rural South Africa: implications for disease control. Am J Public Health 1998; 88: $1243-$ 1245. 